The dates on the documents make a time series analysis possible. The department and position of the sender and receiver of the letters makes a network analysis possible. In short, this metadata collection can be useful to a wide range of research objectives. I hope that it will considerably facilitate the work of almost anyone thinking of consulting the archive, but even separately from the documents that it refers to, it can serve as material for a large-scale digital analysis that can drive any number of analyses of the social, economic, and cultural history of modern Japan.

\section{History and Current State of the Project}

When I first visited the Mitsui Archive in 2011, I spent most of my time working on the Mitsui Bussan archives, the holding company at the center of the prewar Mitsui conglomerate. While looking for a larger archive that would lend itself to a large-scale analysis, and in consultation with Dr. Kikkawa Yō, the head researcher at the Mitsui Archives, I came upon the Mi'ike Mine archive. Taking advantage of the Mitsui Archive's recent policy change that allowed virtually unlimited reproduction of documents, in 2016 I photographed the documents in the Mi'ike Mine archive. The photographs are of high quality, taken with a 24 MP APS-C camera mounted on tripod and triggered via radio remote. This has resulted in 31,925 images in JPG format of $6000 \times 4000$ pixels each occupying a total of $363 \mathrm{~GB}$ of space.

With generous funding from the University of Pittsburgh Central Research Development, the Special Initiative to Promote Scholarly Activities in the Humanities, the Social Science Research Initiative, and most importantly the Asian Studies Center, I put together a team of research assistants to help me input the material in this archive. This has required developing a manual with instructions on how to input the data, an Excel spreadsheet with multiple drop-down lists and macros, and scheduling office hours during which assistants could come and consult about how to read and enter information from the sources. Managing the assistants is a team leader with extensive experience reading cursive handwriting (kuzushiji), who corresponds with the assistants, checks their work, and works on maintaining the accuracy and uniformity of the entries.

\section{The Online Publication of the Index}

The final product of this project will be a spreadsheet containing an estimated nineteen-thousand lines, each representing one document in the Mitsui Mi'ike Mine archive. An estimated 60 percent of these documents will be letters and the rest will be a variety of other documents, including telegrams, envelopes, memoranda, budgets, participant lists, and maps. The spreadsheet will be posted online in 2023, in an open data depository and in accordance with the FAIR data principles that will ensure that it is Findable, Accessible, Interoperable, and Reusable. It will also be supplemented by a description, a data dictionary, and other notes that will contextualize it and facilitate its use.

The spreadsheet will be advertised on social media, including on my academia.edu site, https://pitt.academia.edu/RajaAdal. I very much hope that this project and the conscientious and systematic work of the research assistants who are working to complete it can be of use to researchers working on modern Japan.

\section{(cc) $\mathrm{Br}$}

New articles in this journal are licensed under a Creative Commons Attribution 3.0 United States License.

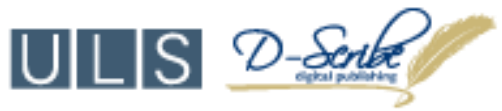

This journal is published by the University Library System, University of Pittsburgh as part of its D-Scribe Digital Publishing program and is cosponsored by the University of Pittsburgh Press. 